\title{
Glycemic Control in Pregnancies Complicated by Pre-Existing Diabetes Mellitus and Congenital Malformations: A Danish Population-Based Study
}

\author{
Linn Håkonsen Arendt (iD ${ }^{1-3}$ \\ Lars Henning Pedersen ${ }^{1,4}$ \\ Lars Pedersen ${ }^{5}$ \\ Per Glud Ovesen (ID) 1,6 \\ Tine Brink Henriksen (iD ${ }^{7}$ \\ Morten Søndergaard Lindhard ${ }^{8}$ \\ Jørn Olsen ${ }^{2,5}$ \\ Henrik Toft Sørensen (iD ${ }^{5}$ \\ Cecilia Høst Ramlau-Hansen (iD) ${ }^{2}$ \\ 'Department of Obstetrics and \\ Gynecology, Department of Clinical \\ Medicine, Aarhus University Hospital, \\ Aarhus, Denmark; ${ }^{2}$ Department of Public \\ Health, Research Unit for Epidemiology, \\ Aarhus University, Aarhus, Denmark; \\ ${ }^{3}$ Department of Obstetrics and \\ Gynecology, Regional Hospital Horsens, \\ Horsens, Denmark; ${ }^{4}$ Department of \\ Biomedicine, Aarhus University, Aarhus, \\ Denmark; ${ }^{5}$ Department of Clinical \\ Epidemiology, Aarhus University \\ Hospital, Aarhus, Denmark; ${ }^{6}$ Steno \\ Diabetes Center Aarhus, Aarhus \\ University Hospital, Aarhus, Denmark; \\ ${ }^{7}$ Department of Child and Adolescent \\ Health, Aarhus University Hospital, \\ Aarhus, Denmark; ${ }^{8}$ Department of Child \\ and Adolescent Health, Regional Hospital \\ Randers, Aarhus, Denmark
}

\begin{abstract}
Purpose: To study the occurrence of major congenital abnormalities in children of women with type 1 and type 2 diabetes and investigate the association between glycated haemoglobin (HbA1c) and major congenital malformations according to type 1 diabetes and type 2 diabetes separately.
\end{abstract}

Patients and methods: In this register-based study, all singletons born alive from January 1, 2000 to December 31, 2015 in the North Denmark and Central Denmark regions of Denmark and their mothers were included. We used data from Danish health registers and the LABKA database. Logistic regression models were used to compute crude and adjusted prevalence odds ratios (cORs and aORs) with $95 \%$ confidence intervals (CIs) for major congenital malformations overall and for subtypes, by type of maternal pre-existing diabetes and $\mathrm{HbA1c}$ levels.

Results: Among 314,245 infants included, 2020 (0.64\%) had mothers with type 1 diabetes and $498(0.16 \%)$ had mothers with type 2 diabetes. We found an aOR of 2.9 (95\% CI: 2.5 , $3.5)$ and 1.9 (95\% CI: $1.3 ; 2.8)$ for major malformations for type 1 and type 2 diabetes, respectively. The highest occurrence was seen for major congenital heart diseases, but we also observed higher occurrence of several other non-cardiac malformations. For both type 1 and type 2 diabetes, the prevalence of major congenital malformations increased with higher levels of maternal HbAlc with no safe threshold level. Mothers with type 1 diabetes had higher risks than those without diabetes irrespective of $\mathrm{HbAlc}$, and women with $\mathrm{HbA} 1 \mathrm{c}$ levels $\geq 9.5 \%$ had 8 times the odds of major congenital malformations [aOR 8.7 (95\% CI: $5.4 ; 14.5)]$.

Conclusions: The prevalence of major congenital malformations progressively increased with poorer glycemic control during pregnancy, with no obvious safe threshold level, for both type 1 and type 2 diabetes.

Keywords: congenital heart diseases, diabetes, epidemiology, malformations, pregnancy, register-based research

\section{Introduction}

Diabetes mellitus remains a major health concern, with an increasing incidence among women of reproductive age. ${ }^{1,2}$ In pregnancies complicated by pre-existing diabetes, women and their offspring face higher risks of adverse pregnancy outcomes, including congenital malformations. Despite advances in prenatal diabetic care, the risk of congenital malformations remains much higher than in the general population.
Correspondence: Linn Håkonsen Arendt Department of Obstetrics and Gynecology, Aarhus University Hospital, Aarhus,

Denmark; Department of Public Health, Research Unit for Epidemiology, Aarhus, Denmark

Tel +45272l 098 I

Email Iha@clin.au.dk 
While it is well known that children born of women with type 1 diabetes face higher risk of congenital malformations and that high glucose concentrations are the primary major teratogen, the literature is less robust in terms of the risk of congenital malformations in children of women with type 2 diabetes. Further, the optimal target levels for glycemic control in pregnancies of women with pre-existing diabetes are controversial and the therapeutic thresholds recommended in different countries' clinical guidelines vary accordingly.

In 2017, Eriksen et al reviewed the existing nine studies on the association between glycemic control in pregnancies affected by type 1 diabetes and congenital malformations. ${ }^{3}$ Overall, they reported an association between $\mathrm{HbAlc}$ and congenital malformations. However, most studies were small with limited statistical power and only had the ability to study congenital malformations overall, with $\mathrm{HbAlc}$ in broad categories, and with limited confounder control. In 2018, a large Swedish registerbased study showed a strong association between $\mathrm{HbAlc}$ and major cardiac malformations in women with type 1 diabetes. ${ }^{4}$ They found no increased risk of major noncardiac malformations but had limited statistical power and did not have the ability to study specific types of malformations.

Thus, the current literature for type 1 diabetes points toward a progressively increased risk of congenital malformations with poorer glycemic control, but this knowledge is currently based on few and mainly small studies and there is a need for larger studies exploring the association in more detail. Furthermore, to the best of our knowledge, no study has assessed the association between $\mathrm{HbAlc}$ and congenital malformations in women with type 2 diabetes.

Therefore, we aimed to investigate the occurrence of major congenital malformations in offspring of women with pre-existing diabetes, while studying subtypes of major congenital malformations and according to type of diabetes. Further, we aimed to study the association between level of glycemic control, measured by $\mathrm{HbAlc}$ and major congenital malformations in women with preexisting diabetes, according to type of diabetes.

\section{Patients and Methods}

The study population comprised all singleton children born in the North Denmark and Central Denmark regions between January 1, 2000 and December 31, 2015 with follow-up of all children until December 31, 2016. We excluded children with chromosomal abnormalities, based on the International Classification of Diseases, 10th edition (ICD-10) (please see ICD-10 codes in Table S1) and those born of women diagnosed with gestational diabetes in the index pregnancy (ICD-10: O244, O249).

The Danish Civil Registration System ${ }^{5,6}$ assigns a unique Civil Registration Number to all residents at birth or upon immigration, which permits individual-level data linkage. We linked data from the Danish Medical Birth Register, ${ }^{7}$ the Danish National Patient Register, ${ }^{8,9}$ the Aarhus University Prescription Database, ${ }^{10}$ and the Clinical Laboratory Information System Research Database (referred to as the LABKA database ${ }^{11}$ ).

The Danish Medical Birth Register ${ }^{7}$ gathers data on inhospital and home-based deliveries, including information on maternal medical history, lifestyle, and delivery of the child. From the Danish National Patient Register, ${ }^{8,9}$ we obtained information on all inpatient and outpatient hospital contacts, including date of admission and diagnosis codes, recorded according to ICD-8 from 1978 to 1993 and ICD-10 from 1994 onwards. The Aarhus University Prescription Database contains data on prescriptions redeemed at all community pharmacies in the North Denmark and Central Denmark regions. The LABKA database $^{11}$ is a computer-based laboratory information system containing the results of all routine blood tests performed in public and private hospitals, as well as ordered by general practitioners in the North Denmark and Central Denmark regions, which serve one-third of the Danish population (approximately 2.2 million inhabitants).

\section{Ascertainment of Exposures Pre-Existing Diabetes}

We classified women as having type 1 diabetes if they were registered in the Danish National Patient Register with type 1 diabetes (ICD-8: 249; ICD-10: E10, O240) until two weeks post-partum, or women with two or more redeemed prescriptions for insulin (A10A) prior to delivery. We classified women as having type 2 diabetes if they were registered in the Danish National Patient Register with this diagnosis (ICD8: 250; ICD-10: E11, O24.1) until two weeks post-partum.

\section{Glycemic Control, Assessed by Glycated Haemoglobin (HbAlc)}

We obtained measurements of HbA1c from the LABKA database from estimated conception of birth. The estimated conception was calculated by subtracting the gestational age in days minus two weeks from the date of 
delivery. If more than one $\mathrm{HbA1c}$ value was recorded, we used the first, as the exposure window of interest is early pregnancy.

We assessed HbAlc continuously and in categories based on predefined levels. For type 1 diabetes, we used the following six categories of HbA1c: $<5.5,5.5$ to $<6.5$; 6.5 to $<7.5 ; 7.5$ to $<8.5 ; 8.5$ to $<9.5$; and $\geq 9.5 \%$. For type 2 diabetes, we used five categories due to lower power: $<5.5 ; 5.5$ to $<6.5 ; 6.5$ to $<7.5 ; 7.5$ to $<8.5$; and $\geq 8.5 \%$.

\section{Ascertainment of Outcomes}

Information on congenital malformations diagnosed at or after birth was available from the Danish National Patient Register from January 1, 2000 until December 31, 2017 allowing a minimum of two-year follow-up of all children. The main outcome of interest was major congenital malformations overall, categorized using ICD-10, in accordance with the European Surveillance of Congenital Malformations (EUROCAT) classification (Table S1).

We further studied major congenital heart diseases and other congenital malformations subdivided into the following: nervous system, eye, ear, face or neck, orofacial clefts, respiratory system, digestive system, abdominal wall defects, urinary system, genital organs, musculoskeletal system, and other congenital malformations. If an infant was born with both a major and a minor malformation, they were coded as having the major malformation. Infants with more than one major malformation were included in more than one category.

\section{Statistical Analyses}

We computed the prevalence with $95 \%$ confidence intervals (CIs) of congenital malformations among children born of women without diabetes and children of women with pre-existing diabetes (both type 1 and type 2 diabetes), as well as according to HbAlc levels. We used logistic regression to compute the crude prevalence odds ratio and adjusted prevalence odds ratio (aOR) with $95 \%$ CIs for major congenital malformations overall and for subtypes. First, we studied the risk of major malformations according to type of maternal pre-existing diabetes in the whole population of offspring, comparing children of mothers with diabetes to children of mothers without diabetes. Second, we studied the risk of major congenital malformations according to the predefined levels of HbAlc $(<5.5,5.5$ to $<6.5 ; 6.5$ to $<7.5 ; 7.5$ to $<8.5 ; 8.5$ to $<9.5$; and $\geq 9.5 \%$ for type 1 diabetes and $<5.5 ; 5.5$ to $<6.5$; 6.5 to $<7.5 ; 7.5$ to $<8.5$; and $\geq 8.5 \%$ for type 2 diabetes).
Here, we fitted two models with different reference groups to explore the risk of major congenital malformations, both within women with diabetes and compared to the general population without diabetes.

In model 1, we compared the prevalence within the group of women with diabetes, using the lowest $\mathrm{HbA1c}$ level $(<5.5 \%)$ as reference group. In model 2, women without diabetes served as the reference group. The analyses were performed allowing for clustering under the mothers' identification number, and analyses were adjusted for maternal age, maternal cigarette smoking during pregnancy, parity, and year of delivery, categorized as shown in Table 1. In a subset, we further adjusted for maternal body mass index in early pregnancy, which was available from 2004 to 2016. Finally, we included HbA1c levels as a continuous variable in the regression model and estimated the risk of major congenital malformations overall, as a function of HbAlc level.

We also performed sub-analyses. First, we restricted the analyses to women with $\mathrm{HbA1c}$ measurements within the first 140 days after conception. This allowed us to evaluate whether estimates changed when only measurements made during the time of organogenesis were used. Second, as there may be a risk of detection bias in analyses restricted to congenital abnormalities diagnosed close to birth, we included all congenital malformations diagnosed up to 5 years post-partum. Third, we repeated the analyses adjusting for hypertensive disorders of pregnancy as preeclampsia and hypertension may be confounding factors.

All analyses were performed using the Statistical Analysis System (SAS) statistical software package, version 9.4. The study was approved by the Danish Data Protection Agency (record number: 2013-41-2096) and Statistics Denmark. According to Danish legislation, Institutional Review Board approval is not required for register-based research.

\section{Results}

After excluding children with chromosomal abnormalities $(n=1422)$ and infants born of women with gestational diabetes $(\mathrm{n}=7226)$, the final study population comprised 314,245 singleton children [153,139 girls (48.7\%) and 161,106 boys $(51.3 \%)]$, who were born alive in the North Denmark and Central Denmark regions between January 1, 2000 and December 31, 2015 (Figure 1). Among them, 2020 children were born to mothers diagnosed with type 1 diabetes and 498 children were born to mothers diagnosed with type 2 diabetes (Table 1). The prevalence of both type 1 and type 2 diabetes 
increased during the study period (Table 1 and Figure 2). Table 1 presents maternal characteristics according to preexisting diabetes status. Compared to mothers without diabetes, those with diabetes were on average older, with higher parity, and more often overweight or obese.

\section{Pre-Existing Diabetes}

In total, 8295 cases of major congenital malformations were observed. Among these, 153 were diagnosed in children whose mothers had type 1 diabetes and 26 were diagnosed in children whose mothers had type 2 diabetes (Table 2).

\section{Type I Diabetes}

Among children of mothers with type 1 diabetes, we found an overall aOR for malformations of 2.9 (95\% CI: 2.5, 3.5) compared to unexposed children. The highest prevalences among exposed children were observed for major congenital heart diseases [aOR: 5.0 (95\% CI: 4.1; 6.2)], major eye malformations [aOR: $2.9(95 \% \mathrm{CI}: 1.4 ; 6.1)$ ], major malformations of the respiratory system [aOR: $2.7(95 \%$ CI: $0.9 ; 8.5)]$ and major malformations of the digestive system [aOR: 2.0 (95\% CI: 1.0; 4.3)] (Table 2).

\section{Type 2 Diabetes}

Children born to mothers with type 2 diabetes had $90 \%$ increased odds [aOR: 1.9 (95\% CI: $1.3 ; 2.8)$ ] of major malformations overall compared to unexposed children. Of the 26 children with major congenital malformations born to mothers with type 2 diabetes, 15 had congenital heart diseases. In regard to type of malformation, we found an aOR of 3.0 (95\% CI: 1.8; 5.0) for major congenital heart diseases. The risks of other subtypes were consistently above 1 , but with CIs overlapping 1 (Table 2).

\section{Glycemic Control}

Measurements of HbA1c were available for $1786(88 \%)$ women with type 1 diabetes and for 397 (80\%) women with type 2 diabetes.

Figure 3 shows the predicted prevalence of malformations in offspring of mothers with pre-existing diabetes according to level of maternal HbAlc. The risk increased substantially with increasing maternal HbAlc. Children of women with HbA1c below $6.5 \%$ also had a higher risk of major congenital malformations compared to the general population.

\section{Type I Diabetes}

For type 1 diabetes, the prevalence of major congenital malformations increased from 4.3\% (95\% CI: $1.8 ; 6.9)$ among children of mothers with HbA1c levels $<5.5 \%$ to
19.8\% (95\% CI: $13.0 ; 26.7)$ among children born to mothers with HbA1c levels $\geq 9.5 \%$. Compared to children of mothers without diabetes, the aORs for major congenital malformations among infants of mothers with type 1 diabetes were 1.4 (95\% CI: $0.4 ; 2.6)$ for $\mathrm{HbA} 1 \mathrm{c}<5.5 \%$, 1.3 (95\% CI: $0.7 ; 2.3)$ for HbA1c 5.5 to $<6.5 \%, 3.0(95 \%$ CI: $2.1 ; 4.3$ ) for HbA1c 6.5 to $<7.5 \%, 3.9$ (95\% CI: 2.6; 6.0) for $\mathrm{HbAlc} 7.5$ to $<8.5 \%, 6.2$ (95\% CI: 3.8 ; 10.2) for HbA1c 6.5 to $<7.5 \%$, and 8.7 (95\% CI: $5.4 ; 14.5)$ for HbA1c $\geq 9.5 \%$ (Table 3, Model 2).

In analyses restricted to women with type 1 diabetes and using $\mathrm{HbA} 1 \mathrm{c}<5.5 \%$ as the reference level, we found that the prevalence of major congenital malformations in offspring increased steadily with $\mathrm{HbA}$ c levels $\geq 6.5 \%$. Compared to HbAlc levels $<5.5 \%$, the aORs were 2.1 (95\% CI: $1.0 ; 4.4)$ for offspring of mothers with an HbA1c measurement between 6.5 and $<7.5 \%$ and 6.1 (95\% CI: $2.7 ; 13.8)$ for offspring of mothers with an HbA1c measurement $\geq 9.5 \%$ (Table 3, Model 1).

\section{Type 2 Diabetes}

For type 2 diabetes, the prevalence of major congenital malformations in offspring also increased with higher levels of maternal HbA1c. For children of mothers with a $\mathrm{HbAlc}$ level $\geq 6.5 \%$, the prevalence was $7.5 \%$ (95\% CI: $2.5 \% ; 12.3 \%$ ) compared to $2.6 \%$ (95\% CI: $2.5 \% ; 2.7 \%)$ among children of mothers without diabetes (Table 3 ).

In analyses comparing infants born to mothers with type 2 diabetes to children of mothers without diabetes, we found a tendency toward higher prevalence of major congenital malformations among the offspring of mothers with type 2 diabetes. The point estimates increased with higher levels of $\mathrm{HbAlc}$, but did not reach statistical significance (Table 3, Model 2).

Similarly, when we examined the association between maternal HbA1c levels and major congenital malformations in offspring within the group of mothers with type 2 diabetes, the risk increased steadily. However, it was statistically significant only for HbA1c levels of $7.5 \%$ to $<8.5 \%$ [aOR: 4.8 (95\% CI: 1.1; 21.4)] (Table 3, Model 1).

\section{Subanalyses}

The results described above did not vary by child gender. When restricting the analysis to HbAlc measurements performed within the first 140 days after conception, the results were similar to the main analysis. Analyses including congenital malformations diagnosed up to 5 years after birth yielded results in the same direction as the main results, but with 
Table I Maternal and Infant Characteristics According to Maternal Diabetes Mellitus Status Among All Singleton Liveborn Infants Born in the North Denmark and Central Denmark Regions, 2000-20I5

\begin{tabular}{|c|c|c|c|c|c|c|c|c|c|c|}
\hline & & & \multicolumn{6}{|c|}{ Maternal Pregestational Diabetes } & \multicolumn{2}{|c|}{ Total Population } \\
\hline & \multicolumn{2}{|c|}{ No Diabetes } & \multicolumn{3}{|c|}{ Type I Diabetes } & \multicolumn{3}{|c|}{ Type 2 Diabetes } & & \\
\hline & $\mathbf{n}$ & $\%^{a}$ & $\mathbf{n}$ & $\%^{\mathbf{a}}$ & Prevalence $^{b}$ & $\mathbf{n}$ & $\%^{a}$ & Prevalence $^{c}$ & $\mathbf{n}$ & $\%^{a}$ \\
\hline $\begin{array}{l}\text { Overall } \\
\text { Maternal characteristics } \\
\text { Maternal age (years) }\end{array}$ & 311,727 & 99.2 & 2020 & 0.64 & 6,43 & 498 & 0.16 & 1.58 & 314,245 & 100.0 \\
\hline $13-24$ & 39,407 & 12.6 & 183 & 9.1 & 4.62 & 20 & 4.0 & 0.50 & 39,610 & 12.6 \\
\hline $25-29$ & 110,890 & 35.6 & 614 & 30.4 & 5.50 & 115 & 23.1 & 1.03 & 111,619 & 35.5 \\
\hline $30-34$ & 110,168 & 35.3 & 713 & 35.3 & 6.42 & 170 & 34.1 & 1.53 & ||$|, 05|$ & 35.3 \\
\hline$\geq 35$ & 51,262 & 16.4 & 510 & 25.2 & 9.81 & 193 & 38.8 & 3.71 & 51,965 & 16.5 \\
\hline \multicolumn{11}{|l|}{ Parity } \\
\hline 0 & 98,583 & 31.6 & 630 & 31.2 & 6.34 & 139 & 27.9 & 1.40 & 99,352 & 31.6 \\
\hline I & 82,602 & 26.5 & 567 & 28.1 & 6.80 & 153 & 30.7 & 1.84 & 83,332 & 26.5 \\
\hline$\geq 2$ & 42,956 & 13.8 & 332 & 16.4 & 7.64 & 146 & 29.3 & 3.36 & 43,434 & 13.8 \\
\hline Missing & 87,586 & 28.1 & 491 & 24.3 & 5.57 & 60 & 12.0 & 0.68 & 88,127 & 28.0 \\
\hline \multicolumn{11}{|l|}{ Cigarette smoking } \\
\hline No & 260,594 & 83.6 & 1655 & 81.9 & 6.30 & 397 & 797 & 1.51 & 262,646 & 83.6 \\
\hline Yes & 46,442 & 14.9 & 308 & 15.2 & 6.58 & 87 & 17.5 & 1.86 & 46,837 & 14.9 \\
\hline Missing & 4691 & 1.5 & 57 & 2.8 & 11.97 & 14 & 2.8 & 2.94 & 4762 & 1.5 \\
\hline \multicolumn{11}{|l|}{ Body mass index $\left(\mathrm{kg} / \mathrm{m}^{2}\right)$} \\
\hline$<18.5$ & 9272 & 3.0 & 21 & 1.0 & 2.26 & 6 & 1.2 & 0.65 & 9299 & 3.0 \\
\hline $18.5-24.9$ & 139,860 & 44.9 & 663 & 32.8 & 4.72 & 92 & 18.5 & 0.65 & 140,615 & 44.7 \\
\hline $25.0-29.9$ & 50,107 & 16.1 & 411 & 20.3 & 8.12 & 112 & 22.5 & 2.21 & 50,630 & 16.1 \\
\hline$\geq 30$ & 29,734 & 9.5 & 484 & 24.0 & 15.89 & 239 & 48.0 & 7.85 & 30,457 & 9.7 \\
\hline Missing & 82,754 & 26.5 & 441 & 21.8 & 5.30 & 49 & 9.8 & 0.59 & 83,244 & 26.5 \\
\hline \multicolumn{11}{|l|}{ Preeclampsia } \\
\hline No & 302,875 & 97.2 & ।,772 & 87.7 & 5.81 & 453 & 91.0 & $\mathrm{I}, 48$ & 305,100 & 97.1 \\
\hline Yes & 8852 & 2.8 & 248 & 12.3 & 27.12 & 45 & 9.0 & 4.92 & 9145 & 2.9 \\
\hline \multicolumn{11}{|l|}{ Hypertension } \\
\hline No & 307,314 & 98.6 & $\mathrm{I}, 868$ & 92.5 & 6.03 & 450 & 90.4 & 1.45 & 309,632 & 98.5 \\
\hline Yes & 4413 & 1.4 & 152 & 7.5 & 32.95 & 48 & 9.6 & $10.4 \mid$ & 4613 & 1.5 \\
\hline \multicolumn{11}{|l|}{ Diabetic complications } \\
\hline No & 311,727 & 100 & I,465 & 72.5 & 4.67 & 472 & 94.8 & 1.50 & 313,664 & 99.8 \\
\hline Yes & 0 & 0 & 555 & 27.5 & 955.24 & 26 & 5.2 & 44.75 & 581 & 0.2 \\
\hline \multicolumn{11}{|l|}{ Infant characteristics } \\
\hline \multicolumn{11}{|l|}{ Gender } \\
\hline Female & $|5|, 92 \mid$ & 48.7 & 972 & 48.1 & 6.35 & 246 & 49.4 & 1.61 & 153,139 & 48.7 \\
\hline Male & 159,806 & 51.3 & 1,048 & 51.9 & 6.51 & 252 & 50.6 & 1.56 & 161,106 & 51.3 \\
\hline \multicolumn{11}{|l|}{ Birth year } \\
\hline 2000-2002 & 59,200 & 19.0 & 286 & 14.2 & 4.81 & 29 & 5.8 & 0.49 & 59,515 & 18.9 \\
\hline 2003-2005 & 58,036 & 18.6 & 320 & 15.8 & 5.48 & 45 & 9.0 & 0.77 & 58,401 & 18.6 \\
\hline 2006-2008 & 57,015 & 18.3 & 334 & 16.5 & 5.81 & 105 & 21.1 & 1.83 & 57,454 & 18.3 \\
\hline 2009-20II & 53,999 & 17.3 & 371 & 18.4 & 6.81 & 132 & 26.5 & 2.42 & 54,502 & 17.3 \\
\hline
\end{tabular}


Table I (Continued).

\begin{tabular}{|c|c|c|c|c|c|c|c|c|c|c|}
\hline & & & \multicolumn{6}{|c|}{ Maternal Pregestational Diabetes } & \multirow{2}{*}{\multicolumn{2}{|c|}{ Total Population }} \\
\hline & \multicolumn{2}{|c|}{ No Diabetes } & \multicolumn{3}{|c|}{ Type I Diabetes } & \multicolumn{3}{|c|}{ Type 2 Diabetes } & & \\
\hline & $\mathbf{n}$ & $\%^{a}$ & $\mathbf{n}$ & $\%^{\mathbf{a}}$ & Prevalence $^{\text {b }}$ & $\mathbf{n}$ & $\%^{a}$ & Prevalence $^{c}$ & $\mathbf{n}$ & $\%^{a}$ \\
\hline $2012-2014$ & 48,786 & 15.7 & 422 & 20.9 & 8.56 & 108 & 21.7 & 2.19 & 49,316 & 15.7 \\
\hline 2015 & 34,691 & $\mathrm{II} . \mathrm{I}$ & 287 & 14.2 & 8.19 & 79 & 15.9 & 2.25 & 35,057 & 11.2 \\
\hline
\end{tabular}

${ }^{\text {a Notes: }}{ }^{\mathrm{a}}$ For maternal and infant characteristics, the column shows the row percentage distribution. Due to rounding to one decimal, the percentages may not add to $100 \%$. brevalence of type I diabetes per 1,000 women. 'Prevalence of type 2 diabetes per 1,000 women

Abbreviation: $n$, number.

slightly attenuated point estimates. Further, when adjusting for hypertensive disorders of pregnancy, the association between pregestational diabetes and major congenital malformations overall was slightly attenuated. For type 1 diabetes, the aOR was 2.7 (95\% CI: 2.3; 3.3), whereas the risk of congenital heart disease was unchanged [aOR 4.7 (95\% CI: 3.7; 5.9)]. When also adjusting for hypertensive disorders of pregnancy in the association between $\mathrm{HbAlc}$ and major congenital

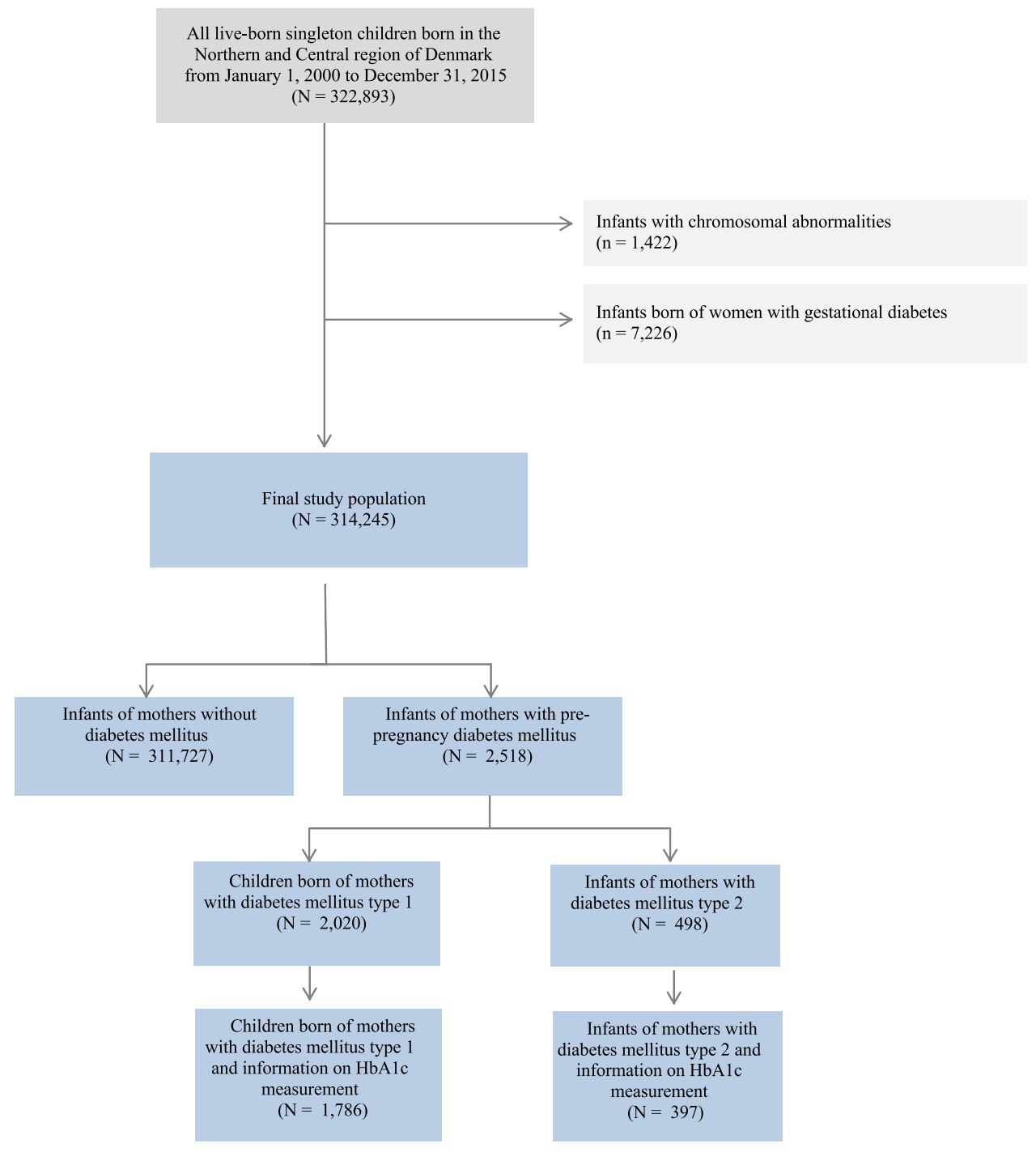

Figure I Flow chart of the study population. 


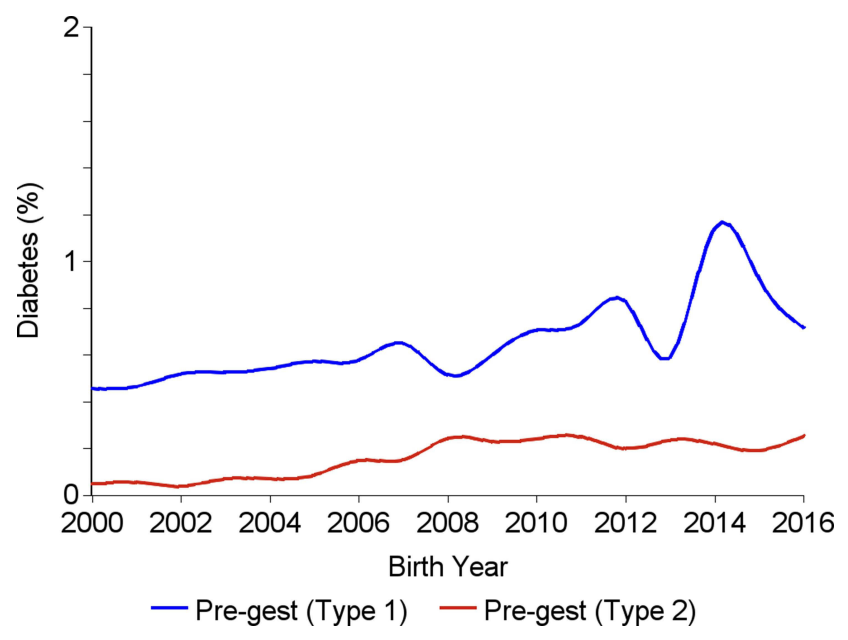

Figure 2 Prevalence of maternal diabetes according to calendar years, among all singleton liveborn infants born in the North Denmark and Central Denmark regions, 2000-2016.

malformations, the association was unchanged with almost identical point estimates for both type 1 and type 2 diabetes (Table S2). Finally, we performed sub-analyses restricted to women with pregestational diabetes and diabetic complications. We overall found stronger associations between pregestational diabetes and major congenital malformations. For type 1 diabetes with diabetic complications, the overall risk of major congenital malformations was 4.4 (95\% CI: 1.3; 14.7). Regarding specific subtypes of malformations, we found that the risk of congenital heart defects was 11.5 (95\% CI: 3.4; 38.7 ) and the risk of malformations of the genital organs was 2.7 (95\% CI: 1.0; 7.3). Furthermore, the association between $\mathrm{HbA1c}$ and major congenital malformations among offspring of women with diabetic complications was stronger, although with wider CIs.

\section{Discussion}

\section{Main Findings}

We found higher occurrence of congenital malformations in children born to mothers with type 1 and type 2 diabetes, with the highest risk of congenital heart defects. Further, we found that the occurrence of major congenital malformations progressively increased with higher levels of $\mathrm{HbAlc}$ for both type 1 and type 2 diabetes. The highest risks were observed for infants of mothers with type 1 diabetes with $\mathrm{HbA} 1 \mathrm{c} \geq 9.5 \%$.

\section{Strengths and Limitations}

This population-based cohort study is among the largest studies investigating the association between $\mathrm{HbAlc}$ in pregnancy and major congenital malformations among offspring of women with type 1 diabetes and the first study assessing $\mathrm{HbA1c}$ and risk of major congenital malformations among offspring of women with type 2 diabetes. A major strength was the large populationbased cohort of Danish health registers known to have high validity, ${ }^{8}$ allowing complete, and long-term followup of the infants. Information on diabetes from the Danish National Patient Register is considered valid, with high positive predictive values for both type 1 and type 2 diabetes. ${ }^{26}$ Another major study strength was use of information on insulin prescriptions to further refine the diabetes classifications. ${ }^{27}$ Further, the validity of congenital malformations has been found to be high, with a positive predictive value of $88 \%{ }^{28}$ Several specific subgroups of malformations have also shown high validity, including congenital cardiac malformations. $^{29-31}$

The LABKA database contains test results for every blood sample analyzed at any public or private hospital or from the general practitioners, with minimal risk of data loss. ${ }^{11}$ Thus, it is reasonable to assume that information on glycemic control was almost complete within our cohort. As HbA1c levels reflect the average blood glucose within the preceding 8-12 weeks, they provide information on long-term glycemic control. For congenital malformations, the critical time period for optimal glycemic control is during organogenesis in the first trimester. In subanalyses, we restricted $\mathrm{HbAlc}$ measurements to the first 140 days of pregnancy.

Our study also has limitations. In registry-based research, the risk of potential confounding is an important consideration. We adjusted for several potential important confounding factors and the crude and adjusted results were similar, but we cannot rule out confounding by unknown factors or residual confounding. We had no information on ethnicity or socio-economic status, which may have resulted in a risk of confounding. We were able to adjust for maternal cigarette smoking and body mass index, but not other lifestyle factors that may increase the risk of major congenital malformations, eg, maternal alcohol consumption and use of recreational drugs. Furthermore, in a sub-analysis, we further adjusted for hypertensive disorders of pregnancy which showed similar results, but we did not take use of medication during pregnancy into account.

We were only able to include live-born children. There is an increased risk of stillbirth in pregnancies complicated 
Table 2 Odds Ratios of Major Congenital Malformations According to Type of Pregestational Diabetes Among 314,245 Live Born Singleton Children, North Denmark and Central Denmark Regions, 2000-20I5

\begin{tabular}{|c|c|c|c|c|c|c|}
\hline & $\begin{array}{l}\text { Type of Diabetes } \\
\text { Mellitus }\end{array}$ & Total $\mathbf{n}$ & $\begin{array}{c}\text { Cases } \\
\mathbf{n}\end{array}$ & $\begin{array}{c}\text { Prevalence } \\
(95 \% \mathrm{CI})\end{array}$ & $\begin{array}{l}\text { Crude OR } \\
(95 \% \mathrm{Cl})\end{array}$ & $\begin{array}{l}\text { Adjusted }^{\mathrm{a}} \text { OR } \\
(95 \% \mathrm{Cl})\end{array}$ \\
\hline \multirow{3}{*}{$\begin{array}{l}\text { Major Congenital Maformations, } \\
\text { Overall }\end{array}$} & No Diabetes Mellitus & 311,727 & 8,116 & $2.6(2.5 ; 2.7)$ & Reference & Reference \\
\hline & Tron I diahoto & 2020 & 153 & $76(64.07)$ & $310636)$ & $20(2535)$ \\
\hline & Type I alabetes & $\begin{array}{c}2,0<0 \\
498\end{array}$ & 56 & $1.0(0.7,0.1)$ & $2.1(2.0-3.0)$ & $2.9(2.3-3.3)$ \\
\hline \multirow{4}{*}{ Nervous System } & & & & & & \\
\hline & No diabetes mellitus & 311,727 & 416 & $0.1(0.1-0.1)$ & Reference & Reference \\
\hline & Type I diabetes & 2.020 & $<5$ & $0.2(0.0-0.4)$ & $1.5(0.6-4.0)$ & $1.6(0.6-4.2)$ \\
\hline & Type 2 diabetes & 498 & $<5$ & $0.4(0.0-1.0)$ & $3.0(0.8-12.1)$ & $3.3(0.8-13.2)$ \\
\hline \multirow[t]{3}{*}{ Eye } & No diabetes mellitus & 311,727 & 373 & $0.1(0.1-0.1)$ & Reference & Reference \\
\hline & Type I diabetes & 2.020 & 7 & $0.3(0.1-0.6)$ & $2.9(1.4-6.1)$ & $2.9(1.4-6.1)$ \\
\hline & Type 2 diabetes & 498 & $<5$ & $0.2(0.0-0.6)$ & $1.7(0.2-12.0)$ & $1.6(0.2-11.5)$ \\
\hline \multirow[t]{3}{*}{ Ear, face, neck } & No diabetes mellitus & 311,727 & 99 & $0.0(0.0-0.0)$ & Reference & Reference \\
\hline & Type I diabetes & 2.020 & $<5$ & $0.1(0.0-0.2)$ & $3.1(0.8-12.7)$ & $3.1(0.8-12.7)$ \\
\hline & Type 2 diabetes & 498 & $<5$ & $0.0(0.0-0.0)$ & $0.0(0.0-I)$ & $0.0(0.0-I)$ \\
\hline \multirow[t]{3}{*}{ Orofacial Clefts } & No diabetes mellitus & 311,727 & 524 & $0.2(0.2-0.2)$ & Reference & Reference \\
\hline & Type I diabetes & 2.020 & 5 & $0.2(0.0-0.5)$ & I.5 (0.6-3.6) & $1.2(0.5-3.3)$ \\
\hline & Type 2 diabetes & 498 & $<5$ & $0.2(0.0-0.6)$ & I. $2(0.2-8.5)$ & I.3 (0.2-9.0) \\
\hline \multirow[t]{3}{*}{ Congenital heart diseases } & No diabetes mellitus & 311,727 & 3048 & $1.0(0.9-1.0)$ & Reference & Reference \\
\hline & Type I diabetes & 2.020 & 101 & $5.0(4.0-6.0)$ & $5.3(4.4-6.5)$ & $5.0(4.1-6.2)$ \\
\hline & Type 2 diabetes & 498 & 15 & $3.0(1.5-4.5)$ & $3.1(1.9-5.3)$ & $3.0(1.8-5.0)$ \\
\hline \multirow[t]{3}{*}{ Respiratory System } & No diabetes mellitus & 311,727 & 156 & $0.1(0.0-0.1)$ & Reference & Reference \\
\hline & Type I diabetes & 2.020 & $<5$ & $0.2(0.0-0.4)$ & $4.0(1.5-10.7)$ & $2.7(0.9-8.5)$ \\
\hline & Type 2 diabetes & 498 & $<5$ & $0.2(0.0-0.6)$ & $4.0(0.6-28.8)$ & $3.2(0.4-23.2)$ \\
\hline \multirow[t]{3}{*}{ Digestive System } & No diabetes mellitus & 311,727 & 541 & $0.2(0.2-0.2)$ & Reference & Reference \\
\hline & Type I diabetes & 2.020 & 7 & $0.3(0.1-0.6)$ & $2.0(0.9-4.2)$ & $2.0(1.0-4.3)$ \\
\hline & Type 2 diabetes & 498 & $<5$ & $0.4(0.0-1.0)$ & $2.3(0.6-9.3)$ & $2.3(0.6-9.3)$ \\
\hline \multirow[t]{3}{*}{ Abdominal wall defects } & No diabetes mellitus & 311,727 & 74 & $0.0(0.0-0.0)$ & Reference & Reference \\
\hline & Type I diabetes & 2.020 & $<5$ & $0.0(0.0-0.1)$ & $2.1(0.3-15.0)$ & $2.5(0.4-18.3)$ \\
\hline & Type 2 diabetes & 498 & $<5$ & $0.0(0.0-0.0)$ & $0.0(0.0-I)$ & $0.0(0.0-I)$ \\
\hline \multirow[t]{3}{*}{ Genital Organs } & No diabetes mellitus & 311,727 & 878 & $0.3(0.3-0.3)$ & Reference & Reference \\
\hline & Type I diabetes & 2.020 & 10 & $0.5(0.2-0.8)$ & I.8 (0.9-3.3) & $1.7(0.9-3.2)$ \\
\hline & Type 2 diabetes & 498 & $<5$ & $0.2(0.0-0.6)$ & $0.7(0.1-5.1)$ & $0.7(0.1-4.7)$ \\
\hline \multirow[t]{3}{*}{ Urinary System } & No diabetes mellitus & 311,727 & 948 & $0.3(0.3-0.3)$ & Reference & Reference \\
\hline & Type I diabetes & 2.020 & 10 & $0.5(0.2-0.8)$ & I.6 (0.9-3.0) & $1.5(0.8-2.8)$ \\
\hline & Type 2 diabetes & 498 & $<5$ & $0.4(0.0-1.0)$ & $1.3(0.3-5.3)$ & $1.3(0.3-5.2)$ \\
\hline \multirow[t]{3}{*}{ Musculoskeletal System } & No diabetes mellitus & 311,727 & 1007 & $0.3(0.3-0.3)$ & Reference & Reference \\
\hline & Type I diabetes & 2.020 & 9 & $0.4(0.2-0.7)$ & I.4 (0.7-2.7) & $1.2(0.6-2.5)$ \\
\hline & Type 2 diabetes & 498 & $<5$ & $0.4(0.0-1.0)$ & $1.2(0.3-5.0)$ & $0.6(0.1-4.3)$ \\
\hline \multirow[t]{3}{*}{ Other Malformations } & No diabetes mellitus & 311,727 & 587 & $0.2(0.2-0.2)$ & Reference & Reference \\
\hline & Type I diabetes & 2.020 & 6 & $0.3(0.1-0.5)$ & I.6 (0.7-3.5) & $1.5(0.7-3.4)$ \\
\hline & Type 2 diabetes & 498 & $<5$ & $0.6(0.0-1.3)$ & $3.2(1.0-10.0)$ & $2.9(0.9-8.9)$ \\
\hline
\end{tabular}

Note: ${ }^{a}$ Adjusted for maternal age, cigarette smoking, parity, and year of birth.

Abbreviations: $\mathrm{Cl}$, confidence interval; $\mathrm{n}$, number; OR, odds ratio. 


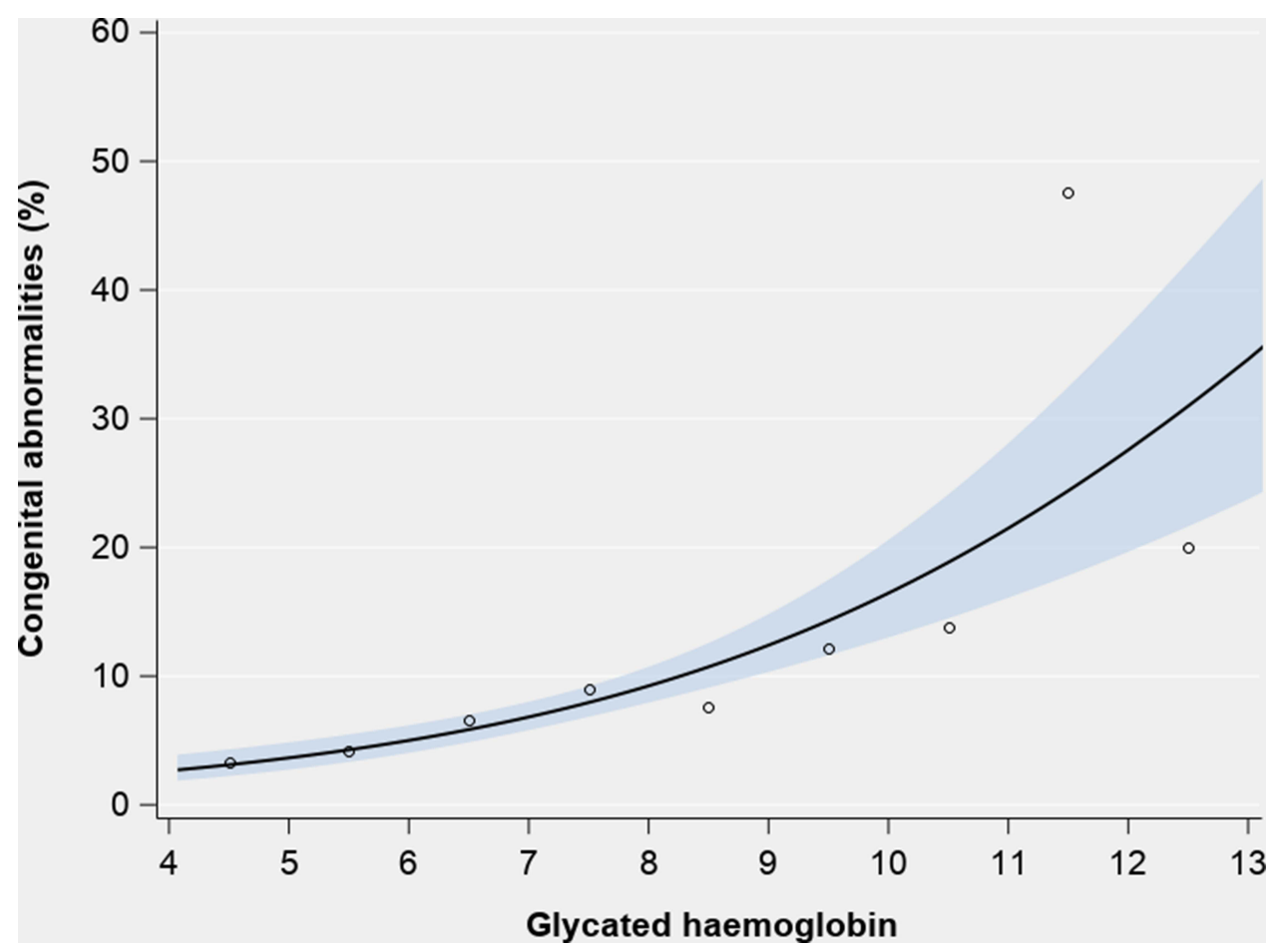

Figure 3 Prevalence (\%) of major congenital malformations according to level of maternal HbAlc among all singleton liveborn infants of mothers with pre-existing diabetes, in the North Denmark and Central Denmark regions, 2000-2016.

by diabetes and the proportion of terminated pregnancies and spontaneous abortions in which fetuses have congenital malformations is considerably higher than in pregnancies resulting in live-born offspring. ${ }^{32}$ The termination of pregnancy after antenatal diagnosis of ie, complex or severe congenital heart defect is a major issue. Due to prenatal death and termination of pregnancies, our results may thus have underestimated the true effect of maternal diabetes and glycemic control on congenital malformations (ie, live-birth bias).

We may not have included all congenital malformations. Whether congenital malformations are diagnosed within the first year of life depend on type and lethality. Some milder malformations may be diagnosed later during childhood. Another important potential limitation is the risk of detection bias. Infants of mothers with diabetes are more closely monitored during pregnancy and postpartum, thus more likely to be diagnosed with congenital malformations. While it is difficult to assess the magnitude of this bias, it may lead to higher risk estimates among offspring exposed to maternal diabetes in pregnancy. We have previously shown that detection bias for congenital malformations minimizes with longer follow-up ${ }^{33}$ and, therefore, we performed sub-analyses with 5 years of follow-up. It is reasonable to expect that major congenital malformations are diagnosed by that age irrespective of maternal diabetes status and results were in the same direction.

\section{Interpretation}

Although it is well known that pre-existing maternal diabetes is associated with increased risk of congenital malformations, ${ }^{12,13}$ the optimal thresholds of glycemic control remain controversial and the recommendations from international clinical guidelines on handling pregnancies complicated by pre-existing diabetes are diverging and rest upon a limited body of evidence. ${ }^{14,15}$

In 2006, Inkster et $\mathrm{al}^{16}$ reviewed the literature and identified 12 studies focused on poor glycemic control and congenital malformations in women with pre-existing diabetes. ${ }^{16}$ Comparing what they defined as poor glycemic control with optimal glycemic control, Inkster et al reported a pooled odds ratio of 3.4 (95\% CI: $2.3 ; 5.2)$. However, the cutoff points of poor versus optimal glycemic control differed substantially in the 12 studies, varying from an $\mathrm{HbAlc}$ of $5.6 \%$ to $10.1 \%$. Timing of HbA1c measurements during pregnancy also differed, making comparisons difficult. Furthermore, most of the studies were small and few could adjust for potential confounders. ${ }^{16}$ 
Table 3 Odds Ratios of Major Congenital Malformations According to Level of HbAlc Among 3I4,245 Live Born Singleton Children, North Denmark and Central Denmark Regions, 2000-2016

\begin{tabular}{|c|c|c|c|c|c|c|c|c|}
\hline \multirow{2}{*}{$\begin{array}{l}\text { Type of } \\
\text { Diabetes }\end{array}$} & \multicolumn{2}{|c|}{ Level of HbAlc, \% } & \multicolumn{2}{|c|}{ Major Malformations } & \multicolumn{2}{|c|}{ Model $I^{a}$} & \multicolumn{2}{|r|}{ Model $2^{b}$} \\
\hline & & & $\mathbf{n}$ & Prevalence & Crude & Adjusted $^{\mathrm{a}}$ & Crude & Adjusted $^{\mathrm{b}}$ OR (95\% \\
\hline \multirow{8}{*}{$\begin{array}{l}\text { No diabetes } \\
\text { Type I diabetes }\end{array}$} & - & 311,727 & 8,116 & $2.6(2.5 ; 2.7)$ & - & - & 1.0 & I.0 (reference) \\
\hline & $<5.5$ & 253 & II & $4.3(1.8 ; 6.9)$ & 1.0 & 1.0 & 1.7 & $1.4(0.9 ; 2.6)$ \\
\hline & & & & & & (reference) & & \\
\hline & $5.5-<6.5$ & 374 & 14 & $3.7(1.8 ; 5.7)$ & 1.0 & $0.9(0.4 ; 2.1)$ & 1.5 & I.3 $(0.7 ; 2.3)$ \\
\hline & $6.5-<7.5$ & 509 & 39 & $7.7(5.4 ; 10.0)$ & 1.8 & $2.1(1.0 ; 4.4)$ & 3.1 & $3.0(2.1 ; 4.3)$ \\
\hline & $7.5-<8.5$ & 334 & 31 & $9.3(6.2 ; 12.4)$ & 2.3 & $2.8(1.3 ; 6.0)$ & 3.8 & $3.9(2.6 ; 6.0)$ \\
\hline & $8.5-<9.5$ & 185 & 21 & II.4 (6.8; I5.9) & 2.8 & $4.6(2.0 ; 10.1)$ & 4.8 & $6.2(3.8 ; 10.2)$ \\
\hline & $\geq 9.5$ & $13 \mid$ & 26 & $19.8(13.0 ; 26.7)$ & 5.4 & $6.1(2.7 ; 13.8)$ & 9.3 & $8.7(5.3 ; 14.5)$ \\
\hline \multirow{7}{*}{$\begin{array}{l}\text { No diabetes } \\
\text { Type } 2 \text { diabetes }\end{array}$} & - & 311,727 & 8,116 & $2.6(2.5 ; 2.7)$ & - & - & 1.0 & I.0 (reference) \\
\hline & $<5.5$ & 116 & $<5$ & $3.4(0.1 ; 6.8)$ & 1.0 & 1.0 & 1.3 & I.7 (0.9; 3.5) \\
\hline & & & & & & (reference) & & \\
\hline & $5.5-<6.5$ & 173 & 9 & $5.2(0.5 ; 5.1)$ & 1.5 & I.3 $(0.4 ; 4.5)$ & 2.1 & $0.5(0.1 ; 3.9)$ \\
\hline & $6.5-<7.5$ & 65 & $<5$ & $4.6(0.0 ; 9.7)$ & 1.4 & $0.5(0.0 ; 4.5)$ & 1.8 & $2.9(0.7 ; 12.2)$ \\
\hline & $7.5-<8.5$ & 27 & $<5$ & II.I (0.0; 23.0) & 3.5 & $2.1(0.3 ; 13.5)$ & 4.7 & 4.8 (I.I; 21.4$)$ \\
\hline & $\geq 8.5$ & 16 & $<5$ & $12.5(0.0 ; 28.7)$ & 4.0 & $4.2(0.7 ; 27.3)$ & 5.3 & $1.7(0.9 ; 3.5)$ \\
\hline
\end{tabular}

Notes: ${ }^{a} \mathrm{I}$ : women with diabetes mellitus and $\mathrm{HbAlc}<5.5 \%$ as the reference group, adjusted for maternal age, cigarette smoking, parity and year of birth. ${ }^{\mathrm{b}}$ Model 2 : women without diabetes mellitus as the reference group, adjusted for maternal age, cigarette smoking, parity and year of birth.

Abbreviations: $\mathrm{Cl}$, confidence interval; $\mathrm{n}$, number; $\mathrm{OR}$, odds ratio.

In 2017, Eriksen et $\mathrm{al}^{3}$ published a systematic review and meta-analyses of studies in the last 20 years that included at least 250 women with pre-existing diabetes. Among the nine included studies, ${ }^{17-25}$ only two distinguished between minor and major malformations. ${ }^{19,25}$ Eriksen et $\mathrm{al}^{3}$ reported that the relative risk of congenital malformations among women with $\mathrm{HbA} 1 \mathrm{c}$ levels between $7.0 \%$ and $8.0 \%$ was $1.9(95 \%$ CI: $1.6 ; 2.3)$ compared to the background population. Recently, a large Swedish registry-based study ${ }^{4}$ explored major cardiac malformations and reported that the risk steadily increased with higher levels of $\mathrm{HbA1c}$, similar to our findings. Even with HbAlc levels below the recommended $6.5 \%$, the risk of major cardiac malformations was more than twofold increased compared to the general population. They did not find an association between $\mathrm{HbAlc}$ levels and risk of major non-cardiac malformations but had limited statistical power.

The 1989 St Vincent Declaration set the goal that outcomes of pregnancies in women with diabetes should approximate those of women in the background population. Even after decades of medical advancement, diabetes remains of major public health and clinical concern in pregnancies. While our and others' results strongly support striving for good glycemic control during pregnancy, there is a lack of international consensus on optimal glycemic control. Currently, the American Diabetes Association recommends an $\mathrm{HbAlc}$ range of $6 \%(42 \mathrm{mmol} / \mathrm{mol})$ to $<7 \%(53 \mathrm{mmol} / \mathrm{mol})^{14}$ and in England, the National Institute for Health and Clinical Excellence (NICE) advises levels as close to 6\% (42 $\mathrm{mmol} / \mathrm{mol}$ ) as possible. ${ }^{15}$ In Denmark, the national guideline recommends an HbAlc level $<6.5 \%$ (47 $\mathrm{mmol} / \mathrm{mol}$ ) during the first half of pregnancy and $5.6 \%$ (38 $\mathrm{mmol} / \mathrm{mol}$ ) during the second half of pregnancy, balancing the concomitant risk of hypoglycemic episodes.

Our results underscore the progressive increase in malformation prevalence with higher levels of HbA1c. Even among those with type 1 diabetes who achieve the recommended optimal HbA1c levels, the prevalence of major congenital malformations remains higher than in children of mothers without diabetes. Thus, it is possible that women affected by type 1 diabetes may never achieve the same risk profile as the background population, reflecting factors other than glycemic control that play an important role for the developing fetus. Future research should study these aspects further. 


\section{Conclusion}

We found that children of mothers with pre-existing diabetes face high risks of major congenital malformations, both cardiac and non-cardiac malformations. Further, the risks of major congenital malformations progressively increased with higher levels of HbAlc for both type 1 and type 2 diabetes.

\section{Author Contributions}

All authors made substantial contributions to conception and design, acquisition of data, or analysis and interpretation of data; took part in drafting the article or revising it critically for important intellectual content; agreed to submit to the current journal; gave final approval of the version to be published; and agreed to be accountable for all aspects of the work.

\section{Funding}

The authors received no specific funding for this project.

\section{Disclosure}

The authors report no financial, personal, political, intellectual or religious conflicts of interest.

The findings have not previously been presented at conferences.

\section{References}

1. McCance DR. Pregnancy and diabetes. Best Pract Res Clin Endocrinol Metab. 2011;25(6):945-958. doi:10.1016/j. beem.2011.07.009

2. Danaei G, Finucane MM, Lu Y, et al. National, regional, and global trends in fasting plasma glucose and diabetes prevalence since 1980 systematic analysis of health examination surveys and epidemiological studies with 370 country-years and 2.7 million participants. Lancet. 2011;378(9785):31-40.

3. Eriksen NB, Damm P, Mathiesen ER, Ringholm L. The prevalence of congenital malformations is still higher in pregnant women with pregestational diabetes despite near-normal HbAlc: a literature review. J Maternal Fetal Neonatal Med. 2017;1-5.

4. Ludvigsson JF, Neovius M, Soderling J, et al. Periconception glycaemic control in women with type 1 diabetes and risk of major birth defects: population based cohort study in Sweden. BMJ (Clinical Research Ed). 2018;362:k2638.

5. Pedersen CB, Gotzsche H, Moller JO, Mortensen PB. The Danish Civil Registration System. A cohort of eight million persons. Dan Med Bull. 2006;53(4):441-449.

6. Schmidt M, Pedersen L, Sorensen HT. The Danish Civil Registration System as a tool in epidemiology. Eur J Epidemiol. 2014;29 (8):541-549.

7. Knudsen LB, Olsen J. The Danish Medical Birth Registry. Dan Med Bull. 1998;45(3):320-323.

8. Schmidt M, Schmidt SA, Sandegaard JL, Ehrenstein V, Pedersen L, Sorensen HT. The Danish National Patient Registry: a review of content, data quality, and research potential. Clin Epidemiol. 2015;7:449-490.
9. Lynge E, Sandegaard JL, Rebolj M. The Danish National Patient Register. Scand J Public Health. 2011;39(7 Suppl):30-33.

10. Ehrenstein V, Antonsen S, Pedersen L. Existing data sources for clinical epidemiology: Aarhus University Prescription Database. Clin Epidemiol. 2010;2:273-279.

11. Arendt JFH, Hansen AT, Ladefoged SA, Sørensen HT, Pedersen L, Adelborg K. Existing data sources in clinical epidemiology: laboratory information system databases in Denmark. Clin Epidemiol. 2020;18(12):469-475.

12. Zhao E, Zhang Y, Zeng X, Liu B. Association between maternal diabetes mellitus and the risk of congenital malformations: a meta-analysis of cohort studies. Drug Discov Ther. 2015;9(4):274-281.

13. Oyen N, Diaz LJ, Leirgul E, et al. Prepregnancy diabetes and offspring risk of congenital heart disease: a nationwide cohort study. Circulation. 2016;133(23):2243-2253.

14. NICE. 2015 Diabetes in pregnancy: management from preconception to the postnatal period https://www.nice.org.uk/guideance/ng3.

15. American Diabetes Association. Management of diabetes in pregnancy: standards of medical care in diabetes. Diabetes Care. 2020;43(Suppl 1):S183-S192.

16. Inkster ME, Fahey TP, Donnan PT, Leese GP, Mires GJ, Murphy DJ. Poor glycated haemoglobin control and adverse pregnancy outcomes in type 1 and type 2 diabetes mellitus: systematic review of observational studies. BMC Pregnancy Childbirth. 2006;6:30.

17. Suhonen L, Hiilesmaa V, Teramo K. Glycaemic control during early pregnancy and fetal malformations in women with type I diabetes mellitus. Diabetologia. 2000;43(1):79-82.

18. Lapolla A, Dalfra MG, Di Cianni G, Bonomo M, Parretti E, Mello G. A multicenter Italian study on pregnancy outcome in women with diabetes. Nutri Metabol Cardiovasc Dis. 2008;18 (4):291-297.

19. Evers IM, de Valk HW, Visser GH. Risk of complications of pregnancy in women with type 1 diabetes: nationwide prospective study in the Netherlands. BMJ (Clinical Research Ed). 2004;328 (7445):915.

20. Jensen DM, Korsholm L, Ovesen P, et al. Peri-conceptional A1C and risk of serious adverse pregnancy outcome in 933 women with type 1 diabetes. Diabetes Care. 2009;32(6):1046-1048.

21. Cyganek K, Hebda-Szydlo A, Skupien J, et al. Glycemic control and pregnancy outcomes in women with type 2 diabetes from Poland. The impact of pregnancy planning and a comparison with type 1 diabetes subjects. Endocrine. 2011;40(2):243-249.

22. Bell R, Glinianaia SV, Tennant PW, Bilous RW, Rankin J. Periconception hyperglycaemia and nephropathy are associated with risk of congenital anomaly in women with pre-existing diabetes: a population-based cohort study. Diabetologia. 2012.

23. Owens LA, Sedar J, Carmody L, Dunne F. Comparing type 1 and type 2 diabetes in pregnancy- similar conditions or is a separate approach required? BMC Pregnancy Childbirth. 2015;15:69.

24. Murphy HR, Steel SA, Roland JM, et al. Obstetric and perinatal outcomes in pregnancies complicated by Type 1 and Type 2 diabetes: influences of glycaemic control, obesity and social disadvantage. Diabetic Med. 2011;28(9):1060-1067.

25. Murphy HR, Bell R, Cartwright C, et al. Improved pregnancy outcomes in women with type 1 and type 2 diabetes but substantial clinic-to-clinic variations: a prospective nationwide study. Diabetologia. 2017;60(9):1668-1677.

26. Thygesen SK, Christiansen CF, Christensen S, Lash TL, Sorensen HT. The predictive value of ICD-10 diagnostic coding used to assess Charlson comorbidity index conditions in the population-based Danish National Registry of Patients. BMC Med Res Methodol. 2011;11:83.

27. Kristensen JK, Drivsholm TB, Carstensen B, Steding-Jensen M, Green A. [Validation of methods to identify known diabetes on the basis of health registers]. Ugeskr Laeger. 2007;169(18):1687-1692. Danish. 
28. Larsen H, Nielsen GL, Bendsen J, Flint C, Olsen J, Sorensen HT. Predictive value and completeness of the registration of congenital abnormalities in three Danish population-based registries. Scand J Public Health. 2003;31(1):12-16.

29. Arendt LH, Ernst A, Lindhard MS, et al. Accuracy of the hypospadias diagnoses and surgical treatment registrations in the Danish National Patient Register. Clin Epidemiol. 2017;9:483-489.

30. Jensen MS, Snerum TM, Olsen LH, et al. Accuracy of cryptorchidism diagnoses and corrective surgical treatment registration in the Danish National Patient Registry. J Urol. 2012;188(4):1324-1329.

31. Agergaard P, Hebert A, Bjerre J, Sorensen KM, Olesen C, Ostergaard JR. Children diagnosed with congenital cardiac malformations at the national university departments of pediatric cardiology: positive predictive values of data in the Danish National Patient Registry. Clin Epidemiol. 2011;3:61-66.
32. Svensson E, Ehrenstein V, Norgaard M, et al. Estimating the proportion of all observed birth defects occurring in pregnancies terminated by a second-trimester abortion. Epidemiology (Cambridge, Mass). 2014;25(6):866-871.

33. Arendt LH, Henriksen TB, Lindhard MS, et al. Hypertensive disorders of pregnancy and genital anomalies in boys: a Danish nationwide cohort study. Epidemiology. 2018;29(5):739-748.
Clinical Epidemiology

\section{Publish your work in this journal}

Clinical Epidemiology is an international, peer-reviewed, open access, online journal focusing on disease and drug epidemiology, identification of risk factors and screening procedures to develop optimal preventative initiatives and programs. Specific topics include: diagnosis, prognosis, treatment, screening, prevention, risk factor modification,

Submit your manuscript here: https://www.dovepress.com/clinical-epidemiology-journal
Dovepress

systematic reviews, risk \& safety of medical interventions, epidemiology \& biostatistical methods, and evaluation of guidelines, translational medicine, health policies \& economic evaluations. The manuscript management system is completely online and includes a very quick and fair peer-review system, which is all easy to use. 